\title{
STRUCTURE
}

\section{AND EVOLUTION OF \\ CLOSE BINARY SYSTEMS}

Edited by P. EGGLETON, S. MITTON, and J. WHELAN
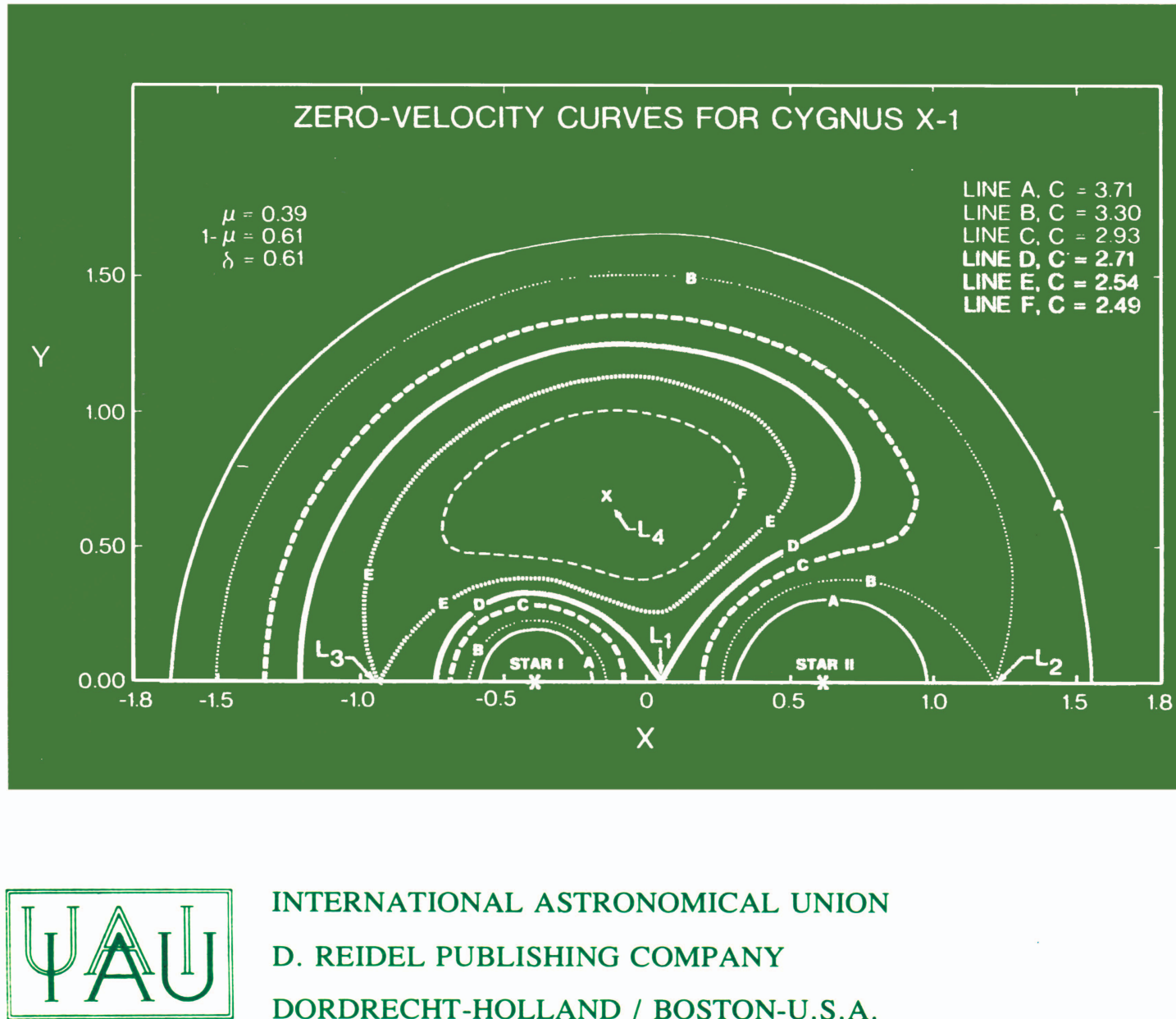

INTERNATIONAL ASTRONOMICAL UNION

D. REIDEL PUBLISHING COMPANY

DORDRECHT-HOLLAND / BOSTON-U.S.A. 


\section{STRUCTURE AND EVOLUTION \\ OF CLOSE BINARY SYSTEMS}

SYMPOSIUM No. 73

This timely symposium was devoted to a field of study that has undergone dramatic revitalisation since the discovery that certain close binary systems are strong $\mathrm{X}$-ray sources. The proceedings contain important review papers and articles that update research on close binaries and, moreover, that indicate the directions in which future advances are likely to be made. The book has many suggestions for important research problems. Major sections are devoted to (a) evolution of massive binaries, (b) the novae and dwarf novae, (c) streams, accretion discs, and Algol-like systems, and (d) contact binary systems and the origin of binaries. Outstanding review papers by B. Warner (Dwarf novae observations), G. T. Bath (Theory of dwarf novae), R. E. Wilson (Black holes), S. Starrfield (Nova explosions), M. Rees (Review of accretion disc problems), and J. Pringle (Close binaries) make this volume essential reading for binary star and variable star enthusiasts. 
STRUCTURE AND EVOLUTION OF CLOSE BINARY SYSTEMS 
INTERNATIONAL ASTRONOMICAL UNION

UNION ASTRONOMIQUE INTERNATIONALE

\title{
SYMPOSIUM No. 73
}

HELD IN CAMBRIDGE, ENGLAND, 28 JULY-1 AUGUST, 1975

\section{STRUCTURE AND \\ EVOLUTION OF CLOSE BINARY SYSTEMS}

\author{
EDITED BY \\ PETER EGGLETON, SIMON MITTON AND JOHN WHELAN \\ University of Cambridge, Institute of Astronomy \\ The Observatories, Madingley Road, Cambridge, England $\mathrm{CB} 3 \mathrm{OHA}$
}

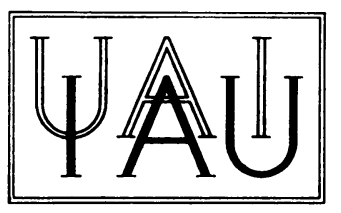

D. REIDEL PUBLISHING COMPANY

DOR D RECHT - HOLLAND / BOSTON-U.S.A.

1976 
Library of Congress Cataloging in Publication Data

Main entry under title:

Structure and evolution of close binary systems.

(Symposium - Inter national Astronomical Union ; no. 73) Includes bibliographies and indexes.

1. Stars, Double-Congresses. I. Eggleton, Peter, 1940- II. Mitton,

Simon, 1946- III. Whelan, John, 1946- IV. Series: International Union. Symposium ; no. 73.

QB821.S85

$523.8^{\prime} 41$

$76-21688$

ISBN 90-277-0682-4

ISBN 90-277-0683-2 pbk.

Published on behalf of

the International Astronomical Union

by

D. Reidel Publishing Company, P.O. Box 17, Dordrecht, Holland

All Rights Reserved

Copyright $\odot 1976$ by the International Astronomical Union

Sold and distributed in the U.S.A., Canada, and Mexico

by D. Reidel Publishing Company, Inc.

Lincoln Building, 160 Old Derby Street, Hingham,

Mass. 02043, U.S.A.

No part of the material protected by this copyright notice may be reproduced or utilized in any form or by any means, electronic or mechanical, including photocopying, recording or by any informational storage and retrieval system, without written permission from the publisher

Printed in The Netherlands 


\section{TABLE OF CONTENTS}

EDITORS' FOREWORD VII

THE ORGANIZING COMMITTEES IX

LIST OF PARTICIPANTS XI

J. SAHADE / Introductory Address 1

J. B. HUTCH IN GS / Massive Binaries - Early Evolutionary Stages 9

H. GURSKY / Binary X-Ray Stars and Supernovae of Type I 19

C. DE LOORE and J. P. DE GRÈV / Two Types of Evolution of Massive Close Binary Systems

E. P. J. VAN DEN HEUVEL / Late Stages of Close Binary Systems

J. P. DE GRÈE, C. DE LoORE, and W. Sut Antyo / The Post-Supernova Stage of Massive Close Binaries: The Possibility of a Tidal Instability 63

R. E. WILsON / The Observational Situation in Regard to Black Holes 65

B. PACZYNSKI / Common Envelope Binaries

R. MITALAS / Effect of Instantaneous Mass Ejection on Orbital Elements of Circular Binaries

J. C. WHEELER and M. LECAR / Tidal Interactions in Compact Binary Systems 83

B. W A R NER / Observations of Dwarf Novae

B. NELSON and A. YOUNG / The Eclipsing Binary White Dwarf BD + $16^{\circ} 516 \quad 141$

N. VOG T / Spectroscopic Observations of Southern Dwarf Novae 147

J. I. SM A K / Spectroscopic Observations of U Gem 149

S. STARRFIELD, W. M. SPARKS, and J. W. TRURAN / The Cause of the Nova Outburst

G. T. BATH / Theory of Dwarf Novae 173

J. FAULKNER / Gravitational Radiation and the Evolution of Low Mass Binaries 193

H. R IT TER / Masses and Evolution of Cataclysmic Binaries 205

P. P. EgGLETON / Angular Momentum Loss and the Origin of Cataclysmic Binaries 209

C.-C. WU / Ultraviolet Observations of some Close Binary Systems by the Astro$\begin{array}{lr}\text { nomical Netherlands Satellite - ANS } & 213\end{array}$

M. J. REES / Accretion Processes in Close Binaries 225

D. N. C. LIN and J. E. PRING LE / Numerical Simulation of Mass Transfer and $\begin{array}{ll}\text { Accretion Disc Flow in Binary Systems } & 237\end{array}$

F. H. SHU / Mass Transfer in Semi-Detached Binaries 253

B. P. FLANNERY / A Hydrodynamical Calculation of Gas Flow in a Cataclysmic Vàriable Star

V. IC KE / Coronae above Accretion Discs 267

Y. KONDO and G. E. M cCLUSKEY / Mass Flow in Close Binary Systems 277

D. S. HALL and S. G. NEFF / Mass Transfer Rates in Algol Binaries Deduced from Their Period Changes 
M. Plavec and R. S. Polidan / The Algols, Red Spectra, Be Stars, and Even Neutrinos

A. H. BATTEN / Notes on the Interpretation of Observations of Circumstellar Matter in Binary Systems

B. W. BALDW IN / Observations of Gaseous Disks in Close Binaries

E. H. GEYER / Starspot Activities as an Interpretation for the Light Curve Changes of the Close Binary Star XY UMa

R. W. HILDITCH and P. W. HILL / Identification of ${ }^{3} \mathrm{He}$ in the Binary System $68 \mathrm{u}$ Her

J. B. HUTCHIN gS / The Mass-Exchange Binary Sco X-1

J. ZIOLKOWSKI/ Evolutionary Status of Massive Algols - a Revision of Classical Theory

R. F. WE B BIN K / Unsteady Mass Loss in Close Binaries

B. P. FLANNERY / A Cyclic Thermal Instability in Contact Binary Stars

A. P. MOSES and R. C. SMITH / Energy Transfer in Contact Binaries

J. A. J. WHELAN / Progress in Contact-Binary Energy Transfer

O. VILHU and T. RAHUNEN / Evolution of Contact Systems

F. VAN'T VEER / The Evolution of Contact Binaries

S. M. RUCINSKI / UBV Photometry of the Shortest Period Contact Binary CC Com

S. M. RUCINS KI / Four-Colour Survey of W-UMa-Type Systems

V. U RECHE / Rotational Angular Momenta of Close Binary System Components

K.-C. LEUNG and R. E. WILSON / An Aspect of Star Fission

V. TRIM BLE and C. CHEUNG / Statistics of Binary Stars: Semi-Major Axes

P. BIERMANN and D. S. HALL / The Origin of the RS CVn Binaries 